Original Article

\title{
IN SILICO STUDIES OF THE SECONDARY METABOLITES OF SOLANUM TORVUM SW. FOR THEIR ANTIASTHMATIC ACTIVITY
}

\author{
SOORYA R. ${ }^{*}$, DHAMODARAN P. ${ }^{1}$, RAJESH KUMAR R. ${ }^{2}$, DURAISAMY B. ${ }^{1}$ \\ 1Department of Pharmacognosy and Phytopharmacy, 2Department of Biotechnology, JSS College of Pharmacy, Ooty, Tamil Nadu 643001, \\ Jagathguru Shri Shivarathreeswara University, Mysore, Karnataka
}

Email: soorya.selvi@gmail.com

Received: 26 Jan 2017, Revised and Accepted: 20 Apr 2017

\begin{abstract}
Objective: Solanum torvum Sw., Family: Solanaceae, commonly known as Turkey Berry is used by the traditional tribes for the treatment of cold, cough, tuberculosis, hepatotoxicity, cancer, etc. The action of the plant towards the treatment of these diseases has been proven except for asthma. The present study is to prove the antiasthmatic activity of methanolic extract and the secondary metabolites of Solanum torvum Sw using in silico docking studies in compare to reference standard Dexamethasone, a synthetic cortisone derivative.
\end{abstract}

Methods: The GC-MS analysis of the dried methanolic extract of the dried fruits of Solanum torvum Sw. and the total saponin fraction has been carried out to know the important moieties that are responsible for the antiasthmatic activity.

Results: The results from the docking studies showed that the compounds Cholesta-5,7,9-(11)-trien-3-ol,4,4-dimethyl, (3á); Lanosta-7,9-(11),20triene-3 $\alpha$, 18-diol, diacetate and Cholestan-26-oic acid,3,7,12,24-tetrakis (acetyloxy), methyl ester, (3à,5á,7à,12à) were found to have significant scores of-6.8,-6.9 and-6.9 respectively towards Glucocorticoid receptor protein (Gr), (PDB id: 4UDC) which is very similar to the affinity of the standard (-7.1). These compounds passed the drug-likeness test. A modification in the structure can be brought, which makes the compounds more potent. The compounds 9, 12-Octadecadienoic acid, ethyl ester; Hexadecanoic acid, ethyl ester; 9-Octadecenoic acid (Z), methyl ester; Oxacycloheptadec-8-en-2-one, (8Z) have passed the Blood Brain Barrier (BBB) filter of the drug-likeness test.

Conclusion: The antiasthmatic activity of the drug may be due to the similarity with the structure of Dexamethasone. Further research can be carried out in order to improve the clinical significance of these extracts and its metabolites.

Keywords: Solanum torvum Sw., Traditional tribes, Antiasthmatic activity, GC-MS analysis, in silico docking studies, Drug-likeness test

(C) 2017 The Authors. Published by Innovare Academic Sciences Pvt Ltd. This is an open access article under the CC BY license (http://creativecommons.org/licenses/by/4.0/) DOI: http://dx.doi.org/10.22159/ijcpr.2017v9i4.20759

\section{INTRODUCTION}

Traditional medicine is "the knowledge, skills and practices based on the theories, beliefs and experiences indigenous to different cultures, used in the maintenance of health and in the prevention, diagnosis, improvement or treatment of physical and mental illness" [1]. The main aim of traditional medicine is to use the resources available from the nature for the treatment of diseases and to maintain the goodness of life.

The Solanaceae or the nightshades are an economically important family of flowering plants. The family ranges from annual and perennial herbs to vines, lianas, epiphytes, shrubs and trees. An important genus of the family is Solanum. This genus consists of a number of medicinal plants which contains unique alkaloids and are medicinally important [2].

Solanum torvum Sw. (Family: Solanaceae), commonly known as Turkey Berry [3] is native to Mexico, Peru and Venezuela. It is widely distributed in Africa, West Indies, India, Bermuda, Indonesia, Malaya, China, Philippines and tropical America [4]. It is used in the folk and traditional medicine for treatment of diseases like asthma, diabetes, gastrointestinal diseases etc. The researches done on Solanum torvum had shown that the plant possesses significant antimicrobial, anticancer, diuretic, anti-inflammatory, anti-influenza activity [5]. The use of the plant to treat asthma by the traditional people is not yet scientifically validated.

Asthma is a common long-term inflammatory disease of the airways of the lungs [6]. It is characterized by recurring symptoms like wheezing, coughing, chest tightness and shortness of breath. These symptoms are due to the reversible airflow obstruction and bronchospasm [7].

Asthma is the result of chronic inflammation of the conducting zone of the airways which result in increased contractibility of the surrounding smooth muscles.
The beneficial effects of glucocorticoids in asthmatic patients were first described in 1950 [8]. Many studies have focused on the therapeutic potential of glucocorticoids. Several synthetic glucocorticoids which are more potent than cortisol without mineralocorticoid side effects have been developed. Nowadays, glucocorticoids are powerful agents in the treatment of inflammatory diseases, allergic conditions and asthma [9].

The effects of inhaled glucocorticoids on bronchial inflammation are studied either by measurements in Bronchoalveolar lavage fluid (BALF), sputum, exhaled air or by performing bronchial biopsies. These studies have confirmed that glucocorticoid treatment of asthmatic patients reduces the number and activation of inflammatory cells in the airways, together with an improvement of lung function. The potent anti-inflammatory actions of glucocorticoids are thought to underlie the clinical efficacy of oral glucocorticoids [10].

\section{Effects of glucocorticoids on lung function}

Treatment with glucocorticoids has been consistently shown not only to reduce the symptoms of asthma but also bronchial hyper responsiveness [11]. In contrast to the rapid inhibitory effects of $\beta_{2^{-}}$ agonists, glucocorticoids given in a single dose are not effective in preventing early allergen-invoked bronchoconstriction, but inhibition of the late response has been clearly demonstrated [12]. The inhaled glucocorticoids consistently reduce airway hyperreactivity in asthmatics [13], but even after several months of treatment responsiveness fails to return to the normal range. This may reflect the persistence of structural changes that can not be reversed by steroids such as the thickening of the basement membrane, despite of suppression of the inflammatory and immunological processes.

The glucocorticoids act by inhibiting the following actions: [9] 
1. T-cell activation

2. Cytokine production

3. Mast cell mediator release

4. Eosinophil mediator release

The synthetic derivatives of glucocorticoid which are used for the treatment of asthma include Dexamethasone, a cortisol derivative and a glucocorticoid agonist [14]. In the present study, Dexamethasone is taken as standard.

The present study aims at proving the antiasthmatic activity of the compounds interpreted in the methanolic extract of the dried fruits Solanum torvum Sw and the saponin fraction of the methanolic extract through in silico docking studies.

\section{MATERIALS AND METHODS}

\section{Collection and authentication of plant material}

The fruits of Solanum torvum Sw. were collected from the tribal village, Thukkanaikanpalayam, Erode, TN and authenticated by the Professor, Department of Herbal plant cultivation, Tamilnadu Agricultural University, Coimbatore.

\section{Extraction of plant material}

The shade dried fruits of Solanum torvum Sw. were powdered and dried at $40^{\circ} \mathrm{C}$ in the hot air oven. The dried powder was extracted in Soxhelet apparatus by continuous hot percolation using $70 \%$ methanol as solvent. After 15-20 syphons the solvent was distilled to obtain the crude extract. The weight of the crude extract was taken and the yield was calculated. This crude extract was used for the further analysis.

\section{Isolation of compounds}

$100 \mathrm{~g}$ of the methanolic extract of the dried fruits of Solanum torvum Sw. was refluxed with petroleum ether, chloroform, ethyl acetate and n-butanol individually for one hour. As per the literature survey the saponin which is present in the Solanum species are fractionated with the help of n-butanol, was filtered and the filtrate was distilled. The filtrate produces a precipitate which is again filtered and the filtrate was evaporated to obtain the saponins. This saponin fraction was further analyzed.

\section{Phytochemical screening}

The qualitative phytochemical tests of the dried methanolic extract of the dried fruits of Solanum torvum Sw. was screened by the method described in Harborne, J. B.1973 [15].

\section{GC-MS analysis}

The compounds interpreted from the GC-MS analysis of the methanolic extract of the dried fruits Solanum torvum Sw and the saponin fraction of the extract are given in table 1 and 2.

\section{In silico docking studies: [16]}

AutoDock is a molecular modelling simulation software. It is especially effective for the protein-ligand docking. The compounds obtained were studied through docking to evaluate their antiasthmatic activity. In the present study, Dexamethasone was taken as standard and the glucocorticoid (Gr) is the target. The results of docking are given in table 3.

\section{Drug-likeness}

The compounds 9,12-Octadecadienoic acid, ethyl ester; Hexadecanoic acid, ethyl ester; 9-Octadecenoic acid (Z), methyl ester; Oxacycloheptadec-8-en-2-one,(8Z); Cholesta-5,7-dien-3-ol,4,4dimethyl, (3á); Cholesta-5,7,9-(11)-trien-3-ol,4,4-dimethyl, (3á); Lanosta-7,9-(11),20-triene-3 $\alpha, 18$-diol, diacetate and Cholestan-26-oic acid,3,7,12,24-tetrakis (acetyloxy), methyl ester, (3à,5á,7à,12à) were tested for the drug-likeness through the DruLiTo software. The DruLiTo is a software which uses the structure of the compound as input and checks for the filters like Lipinski filter, Ghose filter, CMC-50 like the rule, Veber filter, MDDR-like filter, BBB likeness, Unweighted QED and weighted QED. The compound which passes these filters is eligible to be used as a drug.

\section{RESULTS AND DISCUSSION}

\section{Macroscopic evaluation}

The macroscopic evidence of the plant Solanum torvum Sw are as follows.

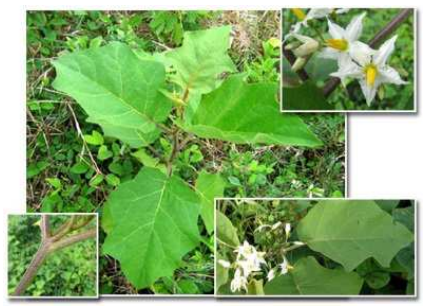

Fig. 1: Solanum torvum Sw

Fruits-The fruits are berries that are yellow when fully ripe. They are thin-fleshed and contain numerous flat, round, brown seeds.

Seeds-Seeds numerous, drab brownish, flattened, discoid, 1.5-2 mm long slightly reticulate, Self-compatible.

Odour-Pepper-like

Taste-Bitter and acrid

\section{Phytochemical screening}

The phytochemical analysis of the methanolic extract of the fruits of Solanum torvum Swartz was performed and the results showed the presence of
1. carbohydrate non-reducing sugars
2. steroids
3. flavonoids
4. glycosides including cardiac glycosides
5. alkaloids
6. saponins

\section{GC-MS analysis}

The compounds interpreted from the GC-MS analysis of the methanolic extract of the dried fruits Solanum torvum Sw and the saponin fraction of the extract are given in the table 1 and 2.

Table 1: The compounds interpreted from the dried methanolic extract of the dried fruits of Solanum torvum Sw

\begin{tabular}{|c|c|c|c|c|}
\hline S. No. & Rt & Compound name & Molecular Formula & CAS No \\
\hline 1. & 15.41 & p-Xylenolphthalein & $\mathrm{C} 24 \mathrm{H} 22 \mathrm{O} 4$ & $50984-88-8$ \\
\hline 2. & 16.36 & $\begin{array}{l}\text { Cholestan-26-oic acid,3,7,12,24-tetrakis (acetyloxy), } \\
\text { methyl ester, }(3 \alpha, 5 \alpha, 7 \alpha, 12 \alpha)\end{array}$ & C36H56010 & $60354-51-0$ \\
\hline 3. & 17.97 & Lanosta-7,9-(11),20-triene-3 $\alpha, 18$-diol, diacetate & С $34 \mathrm{H} 5204$ & $24041-73-4$ \\
\hline 4. & 18.57 & Cholesta-5,7-dien-3-ol, 4,4dimethyl, $(3 \alpha)$ & $\mathrm{C} 29 \mathrm{H} 480$ & $53296-71-2$ \\
\hline 5. & 18.72 & Cholesta5,7,9(11)trien-3-ol, 4,4dimethyl, $(3 \alpha)$ & $\mathrm{C} 29 \mathrm{H} 460$ & $53296-72-3$ \\
\hline
\end{tabular}


Table 2: The compounds interpreted from the saponin fraction of the methanolic extract of the dried fruits of Solanum torvum Sw

\begin{tabular}{|c|c|c|c|c|}
\hline S. No. & Rt & Compound & Molecular formula & CAS No \\
\hline 1. & 16.17 & p-Xylenolphthalein & $\mathrm{C} 24 \mathrm{H} 22 \mathrm{O} 4$ & $50984-88-8$ \\
\hline 2. & 18.18 & Hexadecanoic acid, ethyl ester & С18H3602 & $628-97-7$ \\
\hline 3. & 19.10 & Cholesta-5,7,9-(11)-trien-3-ol,4,4-dimethyl,(3á) & $\mathrm{C} 29 \mathrm{H} 460$ & $53296-72-3$ \\
\hline 4. & 20.03 & 9-Octadecenoicacid (Z), methyl ester & С19H3602 & $112-62-9$ \\
\hline 5. & 20.22 & 9,12-Octadecadienoicacid, ethyl ester & С20H36O2 & $7619-08-1$ \\
\hline 6. & 20.39 & Oxacycloheptadec-8-en-2-one,(8Z) & C16H2802 & $123-69-3$ \\
\hline 7. & 20.66 & Cholesta-5,7-dien-3-ol,4,4-dimethyl,(3á) & C29H480 & $53296-71-2$ \\
\hline 8. & 33.66 & Cholestan-26-oicacid,3,7,12,24-tetrakis (acetyloxy), methyl ester, (3à,5á,7à,12à) & C36H56010 & $60354-51-0$ \\
\hline
\end{tabular}

Table 3 showing the affinity of the compounds obtained from the dried methanolic extract of the dried fruits of Solanum torvum Sw. and the saponin fraction of the extract towards the target

\begin{tabular}{|c|c|c|}
\hline S. No. & Compound name & Affinity towards Glucocorticoid receptor (Gr) \\
\hline 1. & Dexamethasone & -7.1 \\
\hline 2. & 9,12-Octadecadienoic acid, ethyl ester & -3.0 \\
\hline 3. & Hexadecanoic acid, ethyl ester & -3.2 \\
\hline 4. & 9-Octadecenoic acid (Z), methyl ester & -2.7 \\
\hline 5. & Oxacycloheptadec-8-en-2-one,(8Z) & -6.5 \\
\hline 6. & Cholesta-5,7-dien-3-ol,4,4-dimethyl,(3á) & -6.0 \\
\hline 7. & Cholesta-5,7,9-(11)-trien-3-ol,4,4-dimethyl,(3á) & -6.8 \\
\hline 8. & Lanosta-7,9-(11),20-triene-3 $\alpha, 18$-diol, diacetate & -6.9 \\
\hline 9. & Cholestan-26-oicacid,3,7,12,24-tetrakis (acetyloxy), methyl ester, (3à,5á,7à,12à) & -6.9 \\
\hline
\end{tabular}

\section{In vitro docking studies}

The standard Dexamethasone was found to have the affinity of-7.1 towards Gr. The compounds Cholesta-5,7,9-(11)-trien-3-ol,4,4dimethyl, (3á); Lanosta-7,9-(11),20-triene-3 $\alpha$, 18-diol, diacetate and Cholestan-26-oic acid,3,7,12,24-tetrakis (acetyloxy), methyl ester, (3à,5á,7à,12à) are found to have the affinity of-6.8,-6.9 and-6.9 towards Gr which is very similar to the affinity of the standard which is shown in the fig. 2,3,4 and 5.

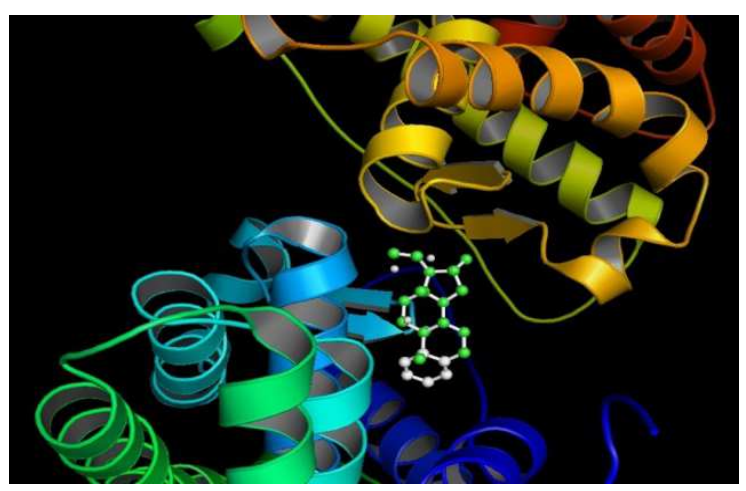

Fig. 2: Docking result of Dexamethasone with Gr

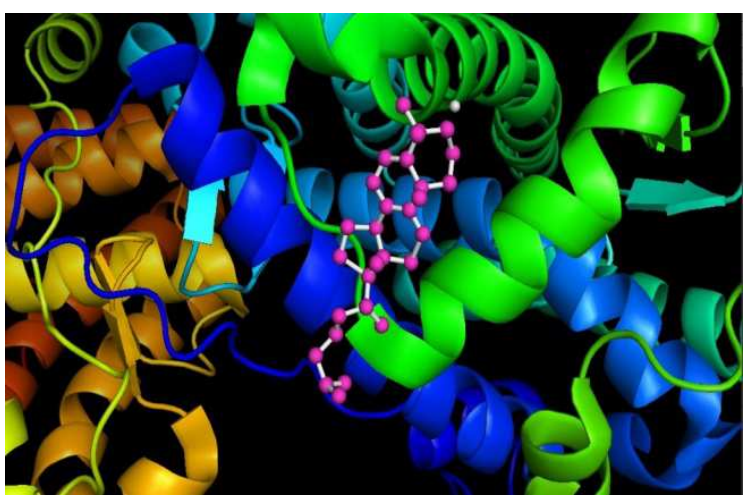

Fig. 3: Docking result of Cholesta-5,7,9-(11)-trien-3-ol,4,4dimethyl, (3á) with Gr

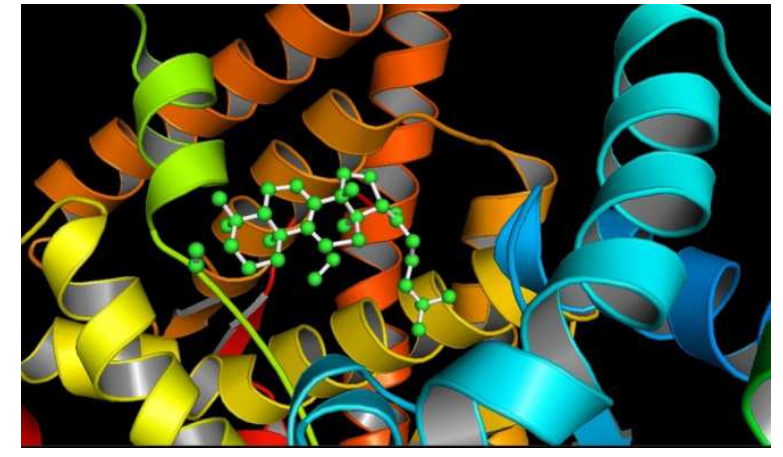

Fig. 4: Docking result of Lanosta-7,9-(11), 20-triene-3 $\alpha$, 18-diol, diacetate with $\mathrm{Gr}$

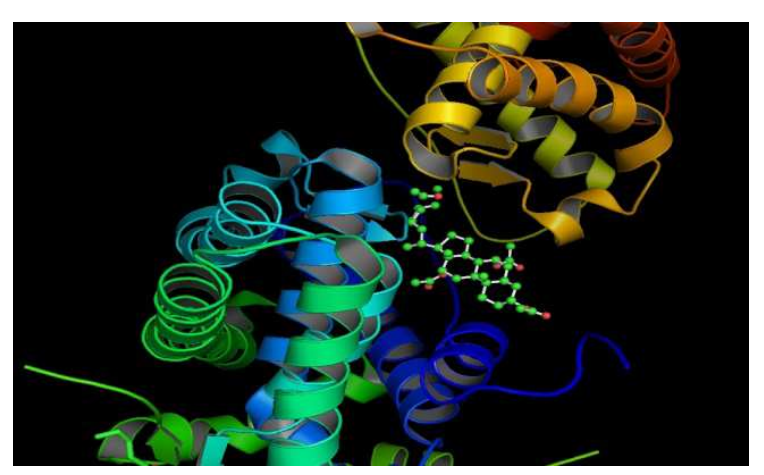

Fig. 5: Docking result of Cholestan-26-oic acid, 3,7,12,24tetrakis (acetyloxy), methyl ester, (3à,5á,7à,12à) with Gr

\section{Drug-likeness}

The compounds 9,12-Octadecadienoic acid, ethyl ester; Hexadecanoic acid, ethyl ester; 9-Octadecenoic acid (Z), methyl ester; Oxacycloheptadec-8-en-2-one,(8Z); Cholesta-5,7-dien-3ol,4,4-dimethyl,(3á); Cholesta-5,7,9-(11)-trien-3-ol,4,4-dimethyl, (3á); Lanosta-7,9-(11),20-triene-3 $\alpha$, 18-diol, diacetate and Cholestan-26-oic acid,3,7,12,24-tetrakis (acetyloxy), methyl ester, (3à,5á,7à,12à) were tested for the drug-likeness through the 
DruLiTo software. The compounds pass the filters which indicate that the drugs are eligible to be used as drugs. A modification in the structure can be brought in the compounds which makes the compounds more potent.

The compounds 9, 12-Octadecadienoic acid, ethyl ester; Hexadecanoic acid, ethyl ester; 9-Octadecenoic acid (Z), methyl ester; Oxacycloheptadec-8-en-2-one,(8Z) has passes the BBB filter.

\section{CONCLUSION}

The plant Solanum torvum Sw was named in 1964. But it is used as a vegetable in our routine diet from the time of our ancestors and also used for the treatment of various diseases including asthma. From the docking and drug likeness study, the results shown are

1. The compounds Cholesta-5,7,9-(11)-trien-3-ol,4,4-dimethyl, (3á); Lanosta-7,9-(11),20-triene-3 $\alpha$, 18-diol, diacetate and Cholestan-26-oic acid,3,7,12,24-tetrakis (acetyloxy), methyl ester, (3à,5á,7à,12à) are found to have the affinity of-6.8,-6.9 and-6.9 towards Gr which is very similar to the affinity of the standard (7.1). These compounds have passed the drug-likeness test.

2. The compounds 9, 12-Octadecadienoic acid, ethyl ester; Hexadecanoic acid, ethyl ester; 9-Octadecenoic acid (Z), methyl ester; Oxacycloheptadec-8-en-2-one, (8Z) have passed the BBB filter.

The present study revealed that the compounds obtained are therapeutically significant and also can be made more potent by further study in the structure activity relationship of the compounds. This study can also be taken as the first step of the research on the antiasthmatic activity of Solanum torvum Sw.

\section{CONFLICT OF INTERESTS}

Declare none

\section{REFERENCES}

1. World Health Organization. Available from: http:// www.who.int/topics/traditional_medicine/en/. [Last accessed on 20 Dec 2016]

2. Pradeep Kumar R. Beneficial effects of solanaceae towards oral health. Res J Pharm Biol Chem Sci 2016;7;1393-6.

3. Ashok D Agarwal, Solanum Torvum Sw. A phytopharmacological review. Pharm Lett 2010;2:403-7.
4. Muhammed Arif, Sheeba Fareed. Pharmacognostical studies and evaluation of total phenolic and flavonoid contents of traditionally utilized fruits of Solanum torvum Sw. India J Nat Prod Resour 2011;2:218-24.

5. Zubaida Yousaf. Phytochemical and pharmacological studies on Solanum torvum Swartz. J Appl Pharm Sci 2013;3;152-60.

6. World Health Organization. Available from: http://www.who. int/topics/traditional_medicine/en/ [Last accessed on 20 Dec 2016].

7. British Guideline on the Management of Asthma; 2009. p. 4.

8. Carryer HM. Effects of cortisone on bronchial asthma and hay fever occurring in subjects sensitive to ragweed pollen. Proc Staff Meet Mayo Clin 1950;25:482-6.

9. VHJ van der Velden. Glucocorticoids: mechanisms of action and anti-inflammatory potential in asthma. Med Inflammation 1998; 7:229-37.

10. Djukanovic R. The effect of treatment with oral corticosteroids on asthma symptoms and airway inflammation. Am J Respir Crit Care Med 1997;155:826-32.

11. Booth H. Effect of high dose inhaled fluticasone propionate on airway inflammation in asthma. Am J Respir Crit Care Med 1995; 152:45-52.

12. Dahl R, Johansson SA. Importance of duration of treatment with inhaled budesonide on the immediate and late bronchial reaction. Eur J Respir Dis Suppl 1982;122:167-75.

13. Barnes PJ. Effect of corticosteroids on airway hyperresponsiveness. Am Rev Respir Dis 1990;141:S70-S76.

14. Culpitt SV. Impaired inhibition by dexamethasone of cytokine release by alveolar macrophages from patients with the chronic obstructive pulmonary disease. Am J Respir Crit Care Med 2003;167:24-31.

15. Harborne JB. Phytochemical methods. In: Preliminary Phytochemical Screening. Chapman and Hall Ltd. London; 1973;1:156-89.

16. Trott 0, Olson A J. AutoDockVina: improving the speed and accuracy of docking with a new scoring function, efficient optimization and multithreading. J Comput Chem 2010;31:455-61.

\section{How to cite this article}

- $\quad$ Soorya R, Dhamodaran P, Rajesh Kumar R, Duraisamy B. In silico studies of the secondary metabolites of Solanum torvum sw. for their antiasthmatic activity. Int J Curr Pharm Res 2017;9(4):38-41. 